Volume 15 - Número 2 - ago/dez de 2020

\title{
OS ERROS DE PONTUAÇÃO DE REDAÇÕES NOTA MIL DO ENEM À LUZ DA HIPÓTESE DA PROSÓDIA IMPLÍCITA E DA FONOLOGIA PROSÓDICA
}

\section{PUNCTUATION ERRORS IN ENEM ESSAYS THAT GRADE FULL MARKS IN LIGHT OF THE HYPOTHESIS OF IMPLICIT PROSODY AND PROSODIC PHONOLOGY}

\author{
Virgínia Silveira Baldow ${ }^{1}$ \\ Alcione de Jesus Santos ${ }^{2}$ \\ Vera Pacheco ${ }^{3}$
}

\begin{abstract}
RESUMO: Este artigo objetiva discutir usos não-convencionais de vírgulas em redações nota mil do ENEM à luz dos pressupostos teóricos da Fonologia Prosódica e da Hipótese da Prosódia Implícita. Com a discussão empreendida, defendemos que o uso não-convencional da vírgula pelos escreventes apresenta regularidades prosódicas que podem ser guiadas pela organização mental da prosódia da fala de que dispõem os falantes que é, de algum modo, projetada para a escrita, fato que também pode explicar as razões pelas quais os avaliadores não se aperceberam das incorreções nos textos investigados. Os resultados mostraram que, embora o uso da vírgula seja associado, em geral, a fatos sintáticos, ela pode atuar como um marcador prosódico, delimitador fronteiras de frases entoacionais. Ressaltamos que os resultados são preliminares, mas apontam questionamentos para continuação do trabalho.
\end{abstract}

PALAVRAS-CHAVE: Vírgula. Prosódia Implícita. Fonologia Prosódica. Escrita. Leitura.

\begin{abstract}
This article aims to discuss non-conventional uses of commas in ENEM essays that grade one thousand points in light of the theoretical assumptions of Prosodic Phonology and the Implicit Prosody Hypothesis. Based on the undertaken discussion, we defend that the unconventional use of the comma by the applicants presents prosodic regularities that can be guided by the mental organization of the speech prosody that the speakers have, which is, in some way, designed for writing, a fact that also explains the reasons why the evaluators were not aware of the inaccuracies in the investigated texts. The results showed that, although the use of the comma is generally associated with syntactic facts, it can act as a prosodic marker, delimiting the boundaries of intonational phrases. We emphasize that the results are preliminary, but point to questions for further work.
\end{abstract}

KEYWORDS: Commas. Implicit Prosody. Prosodic Phonology. Reading. Writing.

\section{Considerações iniciais}

Anualmente, o Instituto Nacional de Estudos e Pesquisas (INEP), por meio de Matrizes de referência, estabelece para a prova de redação do ENEM, assim como para as outras áreas, as chamadas competências de área as quais são aferidas por especialistas no processo de correção das provas (BRASIL, 2017). Tais competências requerem habilidades específicas que perpassam, por

\footnotetext{
${ }^{1}$ Doutoranda em Linguística pelo Programa de Pós-graduação em Linguística da Universidade Estadual do Sudoeste da Bahia; E-mail virginiabaldow@gmail.com; Orcid id: http://orcid.org/0000-0002-2474-7091.

${ }^{2}$ Doutoranda em Estudos Linguísticos pela Universidade Federal de Minas Gerais; E-mail alcionejs@yahoo.com.br; Orcid id: http://orcid.org/0000-0001-7364-9212.

${ }^{3}$ Doutora em Linguística pela Unicamp; Professora plena vinculada ao Departamento de Estudos Linguísticos e Literários da Universidade Estadual do Sudoeste da Bahia e ao programa de Pós-graduação em Linguística e ao Profletras da Universidade Estadual do sudoeste da Bahia; E-mail vera.pacheco@gmail.com; Orcid id: http://orcid.org/0000-00027986-7701.
} 
exemplo: o domínio da norma culta na modalidade escrita da língua portuguesa; a compreensão de fatos e opiniões que possam contribuir com a fundamentação das ideias desenvolvidas; a elaboração articulada de argumentos condizentes com o ponto de vista apresentado, em observância à estrutura do texto dissertativo-argumentativo; apresentação de possíveis ações que visem à solução dos problemas discutidos no texto (BRASIL, 2017).

Para cada uma das competências, o avaliador poderá atribuir uma nota entre 0 a 200 pontos, de acordo com a demonstração (ou não) delas no interior do texto. A obtenção da nota mil, portanto, na redação do ENEM, leva-nos a crer que o estudante tenha alcançado, em sua escrita, cada uma delas, de forma plena. A primeira competência solicita que o candidato demonstre, em seu texto, o "domínio da modalidade escrita formal da Língua Portuguesa" (INEP, 2013, p.11). Para isso, é necessário que o escrevente siga à norma padrão, no que se refere, por exemplo, às regras de ortografia, pontuação, translineação, regência verbal e nominal, concordância verbal e nominal, dentre outros mecanismos importantes para uma boa fluência na escrita, sob o ponto de vista da norma culta.

Todavia, ao se analisar cuidadosamente algumas redações nota mil do ENEM, é possível identificar colocações de vírgulas que são expressamente proibidas pela gramática normativa e que, a rigor, inviabilizaria a atribuição da nota máxima na primeira competência e, consequentemente, inviabilizaria igualmente a atribuição da nota mil para essa redação.

Diante dessa constatação, percebe-se que, apesar do rigor da correção, calcada em critérios bem definidos e objetivos, pode haver discrepâncias entre as notas dos avaliadores. Há colocações de vírgulas usadas pelos candidatos que, mesmo em desacordo com a gramática normativa, como por exemplo, vírgula separando verbo e seus complementos, ou ainda, vírgula separando sujeito do predicado, não causam estranhamento aos corretores que estão atentos à adequação ou não dos textos às matrizes de referência que os orientam na correção.

Essa "inobservância" dos corretores aos usos inapropriados de vírgula tendo por base a gramática normativa traz uma evidência robusta sobre o processamento de escrita e leitura. Percebese que a motivação que levou o candidato a colocar a vírgula em desacordo com a gramática tradicional pode ser a mesma que está presente durante a leitura do corretor, de sorte que a colocação dessa vírgula se torna natural tanto para quem escreve quanto para quem lê. Esse fato leva a seguinte pergunta: usos de vírgulas em desacordo com a gramática normativa podem ter motivações prosódicas? A hipótese para essa pergunta é que certos usos de vírgulas em desacordo com a gramática normativa são motivados por questões prosódicas.

Objetiva-se neste trabalho investigar se usos de vírgulas em desacordo com a gramática normativa têm motivações prosódicas. Para isso, será realizado mapeamento de alguns usos de vírgulas em desacordo com a gramática normativa encontrados em redações nota mil e a avaliação prosódica das frases com as vírgulas usadas sem conformidade com a gramática tradicional.

Para embasar as análises prosódicas será usado o modelo prosódico da Fonologia Prosódica de Nespor e Vogel (2007) e as discussões desenvolvidas terão por base os princípios da Hipótese da Prosódia Implícita - HPI (FODOR 2002, 2005). As análises realizadas e discussões desenvolvidas trazem evidencias que endossam a proposta de Cagliari (2002a, 2002b) e Pacheco (2003) de que as vírgulas funcionam como marcadores prosódicos da escrita.

\section{As diversas funções dos sinais de pontuação: sintáticas, semânticas, prosódicas e discursivas}

Os sinais de pontuação são recursos importantíssimos para a organização do texto escrito e seu uso tem funções diversas, tais como organização sintática (BALDWIN; COADY, 1978; CHEN,1988), semântica, representação das variações da fala (KONDO; MAZUKA, 1996, COHEN 
ET AL, 2001). Além disso, podem ser responsáveis pela coerência e coesão do texto (CAGLIARI, 2002b), bem como podem funcionar como delimitadores de unidades rítmicas (CHACON, 1998).

Em consonância com essa motivação multivariada para o uso dos sinais de pontuação, as gramáticas normativas do português brasileiro apresentam justificativas diversas para o uso desses recursos gráficos, dentre as quais destacam-se a reprodução das pausas rítmicas (ROCHA LIMA, 1964; CEGALLA, 2005) e supressão de recursos rítmicos e melódicos da língua falada (CUNHA E CINTRA, 2001). Bechara (2006) alinha-se à Catach (1980) ao afirmar que a pontuação integra um "sistema de reforço da escrita, constituído de sinais sintáticos, destinados a organizar as relações e a proporção das partes do discurso e das pausas orais e escritas. Estes sinais também participam de todas as funções sintáticas, gramaticais, entoacionais e semânticas" (BECHARA, 2006, p. 604). Assim, o modo de conceber e explicar os usos e funções dos sinais de pontuação não é homogêneo, abarcando tanto questões prosódicas quanto aspectos sintáticos.

Para Cagliari (2002), o uso dos sinais de pontuação cumpre desde funções sintáticas, no caso da distinção entre afirmativas e interrogativas, a funções prosódicas, no caso do padrão prosódico próprio de frases interrogativas e afirmativas. Ademais, vê-se que as gramáticas tradicionais definem os sinais de pontuação como tentativas de representar as pausas, o ritmo, as melodias da fala e a entonação. Apesar disso, a orientação de seu emprego quase sempre está ligada à sintaxe ou à semântica (PACHECO, 2003).

A dinâmica de uso dos sinais de pontuação nos textos evidencia que esses recursos gráficos conferem à escrita um ritmo próprio, assim como o da fala, como defende Chacon (1998). De acordo com esse autor, a pontuação refere-se, ainda, à espacialização que aquele que escreve faz da linguagem em várias dimensões simultâneas, a saber, i) na dimensão fônica (associada a pausas, contornos entoacionais, intensidade e duração); ii) na dimensão sintática (associada à delimitação de unidades); iii) na dimensão textual, indicada como a responsável pela organização e coerência textual; iiii) na dimensão enunciativa (ligada à expressividade do escrevente no código semiótico). Todas essas dimensões estão organizadas de forma não isomórfica, unidas por meio da enunciação ao ritmo da escrita e, juntas, formam o aspecto multidimensional da linguagem.

O ritmo da escrita evidenciado pelos sinais de pontuação, como sinaliza Chacon (1998), pode ter sua origem na prosódia presente na circulação do escrevente pela imagem que ele faz da gênese da escrita, conforme defende Corrêa (2004). Na concepção desse autor, a prosódia aparece na escrita somente através da articulação com outros planos como o léxico e a sintaxe, por exemplo. Além disso, quase sempre, a leitura de um texto escrito é feita mediante a imposição, quer seja em voz alta, quer não (considerando que, na leitura silenciosa, o leitor recupera, ainda que mentalmente, os aspectos prosódicos), de uma prosódia. Nesse sentido, a prosódia não é única e exclusivamente da fala, haja vista que se constitui como exigência da leitura, demarcada, também, pelo uso dos sinais de pontuação. Ademais, o leitor poderá, perfeitamente, recuperar a prosódia por meio de diferentes pistas linguísticas deixadas pelo escrevente (CORRÊA, 2004, p.116).

O comportamento prosódico na leitura pode ser sinalizado pelos próprios sinais de pontuação. É nesse sentido que Cagliari defende que os sinais de pontuação juntamente com outros recursos gráficos (paragrafação, usos de negrito, itálico, letras maiúsculas, etc.) devem ser considerados marcadores prosódicos da escrita (CAGLIARI 1989), pois a presença dessas marcas gráficas incita variações prosódicas específicas (CAGLIARI 2002a, 2002b).

Pacheco $(2003,2006)$ corrobora as constatações de Cagliari (1989, 2002a, 2002b) acerca do funcionamento dos sinais de pontuação como marcadores prosódicos da escrita. A autora caracteriza, acusticamente, os sete sinais de pontuação mais comuns do português brasileiro quais sejam: dois pontos, interrogação, ponto e vírgula, reticências, ponto final, exclamação e ponto final, durante leitura oral. A pesquisadora encontrou propriedades acústicas para cada um dos sinais de pontuação investigados. Seus resultados evidenciam que cada sinal de pontuação investigado orienta o leitor 
proficiente a ter um comportamento prosódico específico, endossando a proposta de Cagliari (1989) de que os sinais de pontuação são marcadores prosódicos da escrita, inclusive a vírgula.

Tendo em vista os propósitos deste trabalho, que considera os sinais de pontuação, mais especificamente, a vírgula, do ponto de vista prosódico, serão discutidos os pressupostos da Teoria Prosódica de Nespor e Vogel (2007), enfocando o sintagma entoacional, constituinte mais relevante para os dados aqui analisados. Essa teoria será articulada com a Hipótese da Prosódia Implícita de Fodor (2005).

\section{A fonologia prosódica de Nespor e Vogel (2007)}

Em Prosodic Phonology, de 1986, Nespor e Vogel propõem um estudo de interface entre a Fonologia e outros elementos da gramática, definindo quais elementos fazem parte da composição da fala e se eles são pertencentes ou não a outros domínios linguísticos. Nespor e Vogel (2007) propõem que os constituintes prosódicos também possuem uma organização hierárquica com relações de dominância entre si, assim como na sintaxe. O que diferencia, pois, a fonologia e a sintaxe é o fato de eles dividirem em constituintes, um mesmo pedaço de fala, de forma diferente. Ademais, enquanto as regras sintáticas apresentam naturalmente o caráter da recursividade, as fonológicas não. Portanto, se as estruturas sintáticas são infinitas devido à recursividade, as estruturas prosódicas são, a priori, finitas e menos profundas.

Para Nespor e Vogel (2007), a estrutura prosódica é composta de sete níveis que se organizam hierarquicamente: a sílaba, o pé, a palavra fonológica, o grupo clítico, a frase fonológica, a frase entoacional e o enunciado fonológico. As sílabas e o pé são puramente fonológicos, a palavra fonológica, o grupo clítico e a frase fonológica estabelecem interface com a sintaxe, a frase entoacional e o enunciado fonológico, por outro lado, estão fortemente atrelados a variáveis semânticas e pragmáticas. A escolha dessas categorias é justificada pelo fato de elas constituírem domínios de aplicação de regras fonológicas.

A organização hierárquica a que se referem Nespor e Vogel (2007) é sistematizada em um diagrama arbóreo apresentado por Bisol (2001):

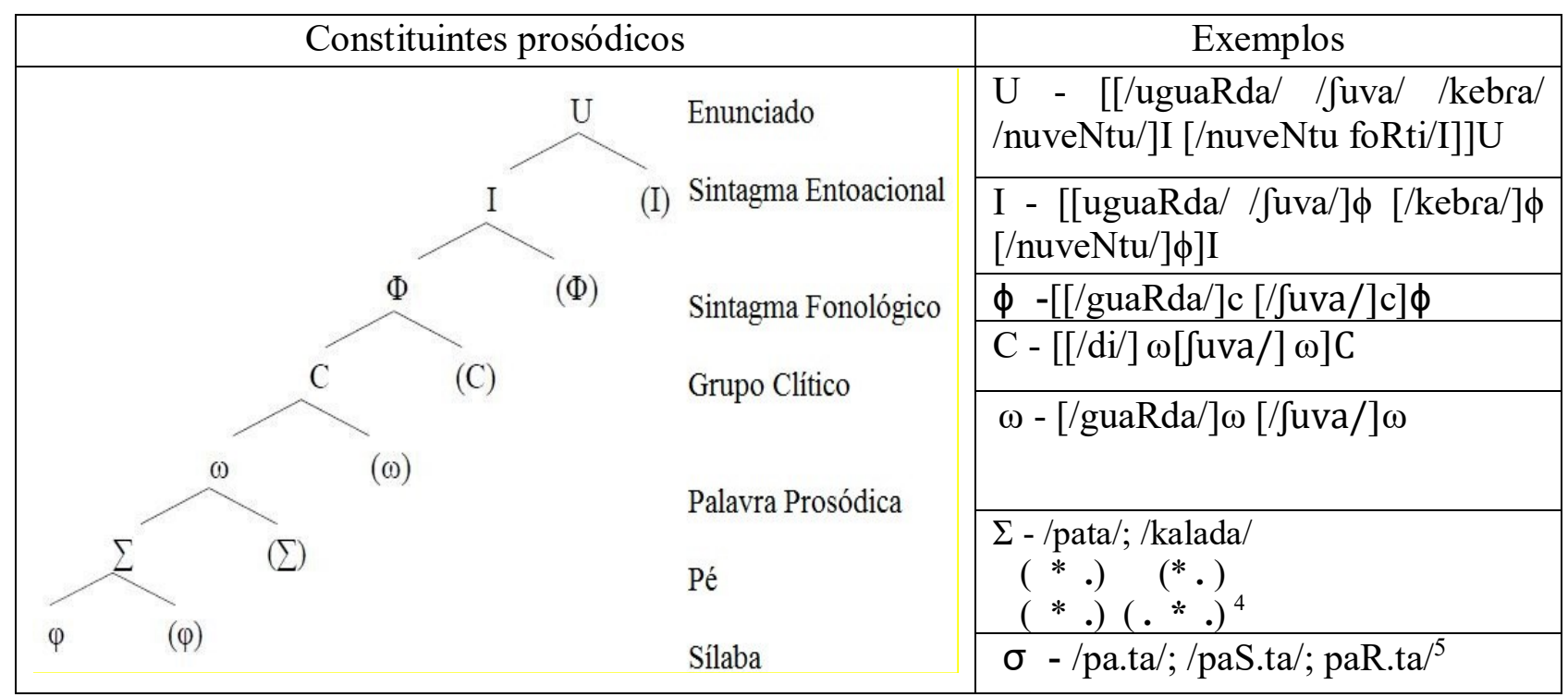

FIG 1: Hierarquia prosódica: Fonte: Adaptado de Bisol (2001, p. 230).

${ }^{4} \mathrm{O}$ pé métrico é a combinação de duas ou mais silábas, observando-se a relação de forte (*) e fraco (.) entre elas.

${ }^{5} \mathrm{O}$ uso de . significa fronteira silábica. Nesse sentido, /pa/ é uma sílaba; /ta/ é outra sílaba e assim por diante. /pa.ta/; $/ \mathrm{paS} . \mathrm{ta} / ; \mathrm{paR} . \mathrm{ta} /{ }^{5}$ 
A inexistência de isomorfismo entre sintaxe e fonologia nos domínios mais altos, como a frase fonológica, pode ser explicada tanto por condições fonológicas quanto por condições discursivas. A tendência é que constituintes muito longos tendem a ser divididos. Essa divisão também pode decorrer da velocidade de fala, sendo sintagmas entoacionais mais longos correspondentes a uma fala mais rápida e sintagmas entoacionais menores correspondentes a uma fala mais pausada. O processo de reestruturação dos sintagmas entoacionais ocorre tanto devido a questões fisiológicas (necessidade de pausas para a respiração) quanto por fatores situacionais e pragmáticos (estilo, grau de formalidade do discurso etc.) Discursos mais formais tendem a dividir uma frase entoacional longa em diversas frases entoacionais curtas, enquanto a fala rápida tende a não ter tantos contornos entoacionais. No entanto, as reestruturações, por razões fonológicas ou semânticas, estão suscetíveis a restrições sintáticas, como a improbabilidade de quebra de NP e separação entre verbo e seu argumento interno. (NESPOR; VOGEL, 2007).

Embora o foco das teorizações empreendidas por Nespor e Vogel (2007) seja voltado para as regras que permitem embasar a seleção dos constituintes prosódicos, as autoras mencionam, também, o papel das pausas e dos contornos entoacionais na constituição da estrutura prosódica, o que é bastante relevante para o trabalho ora empreendido, qual seja, entender como a identificação de mais de um sintagma entoacional pode levar escreventes de redações nota mil do ENEM a demarcarem os sintagmas com a utilização de vírgulas (inadequadas do ponto de vista normativo).

A fonologia prosódica é, segundo as autoras, não apenas uma explicação de como o fluxo da fala é organizado em unidades prosódicas menores, mas também uma teoria da interação entre a fonologia e os domínios da sintaxe, da morfologia e da semântica. Embora os constituintes fonológicos não sejam necessariamente isomórficos a constituintes morfossintáticos, a fonologia é compreendida na sua relação com os outros componentes da gramática.

\section{A hipótese da prosódia implícita de Fodor (2005)}

O termo prosódia implícita é definida por Bader (1998) como sendo um conjunto de informações prosódicas que acompanha a voz interior que escutamos durante a leitura silenciosa. Essa voz interior seria resultante da codificação fonológica, um processo específico da leitura pelo qual a linguagem escrita é associada a representações fonológicas.

Estudos como o de Slowiaczek e Clifton Jr (1980) sugerem a existência da prosódia implícita, demonstrando o papel da subvocalização na compreensão da leitura. Os autores observaram que, quando a subvocalização foi suprimida, a compreensão de conceitos individuais não foi comprometida, todavia, a combinação de ideias e conceitos careceu de subvocalização. Com isso, os pesquisadores lançaram duas hipóteses para os resultados: a hipótese de que a memória propõe que a subvocalização traduz um input visual em código fonológico, sendo que este dura mais na memória do que o código visual; e a hipótese de que a estrutura prosódica sugere que a subvocalização reorganiza o input visual numa representação que fornece pronto acesso à informação necessária ao processamento da sentença.

No nível da sentença, a prosódia compreende três aspectos distintos, a saber, a entonação distribuição de acentos tonais na sentença; o padrão rítmico frasal - distribuição de sílabas fortes e fracas dentro da sentença; e o fraseamento prosódico - divisão da sentença em constituintes prosódicos (SELKIRK, 1995; NESPOR E VOGEL, 2007). Como discutido no tópico anterior, há, nas línguas, diversas possibilidades de fraseamento prosódico que podem ser determinados por desde a estrutura sintática (estrutura de foco) às situações discursivas (estilo, grau de formalidade, velocidade de fala etc.) (BADER, 1998; SELKIRK, 2000; NESPOR; VOGEL, 2007).

Estudos sugerem que, durante a leitura silenciosa, um contorno prosódico default é projetado no estímulo, podendo influenciar a resolução de ambiguidades sintáticas. (LEHISTE,1973; 
MAGALHÃES et. al., 2016). Se não houver contratempo, o parser, compreendido como sendo um mecanismo mental humano de processamento sintático, responsável por mediar a produção e a compreensão da linguagem, favorece a análise sintática associada ao contorno prosódico mais natural para a construção (FODOR, 2005, p. 96.). De acordo com essa hipótese, a análise sintática e a atribuição da prosódia podem estar intercaladas com o processamento prosódico dando prosseguimento ao processamento sintático de baixo nível e alimentando, mais tarde, as decisões sintáticas do parser. Quando o parser toma uma decisão equivocada, ocorre o chamado efeito labirinto (Garden-Path), momento em que o leitor faz um processamento on-line inadequado da sentença, mas imediatamente retoma o processamento adequado (FRAZIER, 1979). Desde o surgimento da HPI, as pesquisas sobre o papel da prosódia como importante pista no processamento de sentenças foram alavancadas, tanto na produção, quanto na compreensão de enunciados.

Com base na suposição de que, durante a leitura silenciosa, os leitores projetam implicitamente sobre o enunciado escrito um contorno prosódico similar ao contorno mais natural daquele enunciado produzido oralmente (FODOR, 2005), pretende-se, no presente estudo, investigar, a partir dos pressupostos da Hipótese da Prosódia Implícita as ocorrências de usos de vírgulas não preconizados pela gramática normativa e não identificadas pelos corretores como uso indevido de vírgula nas correções, do quesito pontuação, de redações nota mil do ENEM.

\section{Metodologia}

Considerando que o presente estudo parte dos princípios propostos pela pesquisa documental, sob a abordagem qualitativa, o processo de geração de dados desta pesquisa foi, assim, proveniente dos seguintes instrumentos e procedimentos:

1. Coleta das redações, do período de 2012-2015;

Foram selecionadas 10 redações das edições 2012 - 2015. O período de seleção se deu em função de questionamentos repercutidos negativamente na mídia, em referência à pontuação atribuída a textos com brincadeiras pejorativas e, por isso, estranhas ao contexto proposto, como receitas de miojo, hino de times, etc. Casos como estes foram recorrentes nas edições escolhidas e nos inquietaram a ponto de voltar o olhar para as redações nota mil, a fim de verificar a pontuação empregada nos textos, mais especificamente, o uso da vírgula, não com o intuito de questionar o mérito da pontuação atribuída às redações, tampouco a competência da equipe de correção, mas com o propósito de tentar explicar, à luz de teorias linguísticas, o que leva os escreventes ao uso nãoconvencional da vírgula, bem como o que faz com que esses usos não-convencionais passem desapercebidos pelos avaliadores.

2. Análise do uso das vírgulas com o intuito de averiguar se, de fato, contemplam às exigências previstas na competência 1 ;

3. Interpretação dos dados encontrados à luz dos pressupostos da gramática normativa, bem como dos pressupostos teóricos da Fonologia Prosódica.

Esta pesquisa constituiu como corpus redações nota mil, produzidas por ocasião do ENEM, edições: 2012-2015. Os textos foram retirados das seguintes fontes: http://oglobo.com/arquivos/redação//enem.pdf;

http://educação.uol.com.br/noticias/2014/04/07;http://blogdoenem.com.br/redacao-enem-nota-1000 https://www.enemvirtual.com.br/redacao-nota-1000-enem/;

http://redacaoenemvestibular.blogspot.com/2013/09/ 
Volume 15 - Número 2 - ago/dez de 2020

\section{Resultados}

As orientações de não uso da vírgula são motivadas, sobretudo por questões sintáticas, a exemplo de não se separar sujeito de predicado, para separar orações coordenadas que não têm conectivos, separar orações coordenadas sindéticas iniciadas pelas conjunções adversativas, alternativas, conclusivas ou explicativas entre outras. No entanto, a vírgula pode atuar como um marcador prosódico.

Apesar dessas proibições de usos e não usos, é muito comum encontrar em texto de pessoas com domínio da escrita padrão usos indevidos de vírgula. Assim também acontece com as redações nota mil do ENEM, como mostram as análises aqui realizadas. Nesse sentido, ressaltamos questão fundamental: os deslizes nas colocações de vírgulas cometidos por candidatos do ENEM, autores de redação nota mil, ou por qualquer outro escritor com domínio da norma escrita padrão, são arbitrários ou têm outras motivações? Essas questões podem ser discutidas a partir de confronto entre vieses, quais sejam: i) do ponto de vista sintático-normativo; ii) do ponto de vista da Fonologia Prosódica, conforme apresentado nas próximas seções. Ressaltamos que a maioria das redações das quais foram retirados os exemplos explorados pelo presente estudo apresenta outros trechos em que se percebem erros de pontuação, sobretudo em relação ao uso da vírgula, seja pelo uso indevido ou pela não inserção desse sinal de pontuação onde ele seria necessário. Desse modo, não se pode dizer que os desvios aqui investigados foram uma excepcionalidade, sendo observadas reincidências. Esses outros problemas de pontuação não foram explorados aqui por uma questão de espaço, mas os interessados podem acessar as redações, para verificação, no link disponibilizado na metodologia.

Categoria 1: vírgula separando verbo e complementos

Um dos usos indevidos encontrados nas redações nota mil do ENEM foi a vírgula separando verbo e complementos, como exemplo em a, b e c:

a) “[...] cabe ao governo do Haiti e de outros países, trabalhar por melhores condições de subsistência, [...]."

Em 1 a), o objeto indireto aparece de forma anteposta ao objeto direto, o que pode dificultar ao escrevente o uso adequado da vírgula, de modo que ele separa o verbo dos seus complementos. Verificamos no trecho que o verbo caber é bitransitivo, exigindo dois objetos: um objeto direto e outro indireto. Cabe algo (o objeto direto) a alguém (o objeto indireto), ou seja, cabe o quê? Trabalhar por melhores condições de subsistência (objeto direto); a quem cabe? Ao governo do Haiti e de outros países (objeto indireto). Do ponto de vista da gramática normativa, não cabe o uso da vírgula entre o verbo e seus complementos, nem entre termos integrantes da oração, nesse caso, dos objetos.

Contudo, esses constituintes sintáticos, verbos e seus complementos, são separados com vírgula, porque, mentalmente, cada um deles possui contornos prosódicos próprios e definidos, ou seja, cada um deles constitui, em termos prosódicos, um sintagma entoacional (I), sendo possível verificar a segmentação do enunciado em duas partes:

[Cabe ao governo do Haiti e de outros países]I [trabalhar por melhores condições de subsistência]I

O fato de o escrevente identificar dois sintagmas entoacionais como se observa em 1 a), levao a introduzir uma vírgula entre o sujeito e o predicado, o que é considerado um erro de pontuação. Essa vírgula corresponde à percepção da existência de um limite (ou uma fronteira) de sintagma 
entoacional que divide, do ponto de vista prosódico, os dois sintagmas. Em 1 b) é possível perceber também a influência de fraseamento prosódico sobre o trecho.

Considerando o trecho de 1 a), é importante ressaltar que as fronteiras das Is (frases entoacionais) tanto podem estar relacionadas a pausas e a contornos entoacionais como também a ênfases prosódicas. Em 1 b), a vírgula é empregada com o intuito de dar ênfase prosódica ao trecho que a sucede, o que indica que em [cabe ao governo do Haiti e de outros países,] a vírgula funciona como um marcador de um contorno focalizador e indica, em termos semânticos, o modo como a informação subsequente deve ser interpretada. A vírgula, nesse caso, marca que o foco destacado pelo escrevente é a ação a ser realizada pelo governo qual seja, [trabalhar por melhores condições de subsistência].

b) $[. .$.$] No entanto, o que se observa em diversas partes do país, é a gritante diferença entre$ os salários de homens e mulheres, principalmente se estas foram negras.

À semelhança do entendimento normativo apresentado na análise empreendida em 1 a), a oração subordinada substantiva que complementa o sentido da oração principal, em 1 b), exerce a função de objeto direto, ou seja, ela integra a oração precedente, não sendo, assim, permitido o uso da vírgula. Entretanto, motivações de ordem prosódica levam o escrevente a segmentar o enunciado em partes (marcando fronteiras prosódicas) como ilustrado a seguir:

[No entanto]I [o que se observa em diversas partes do país]I [é a gritante diferença entre os salários de homens e mulheres]I [principalmente se estas foram negras]I

Verificamos no trecho a existência de quatro Is (frases entoacionais). Conforme Tenani (2002), quando uma sentença neutra é formada por mais de uma $\mathrm{I}$, as Is não-finais dessa sentença são caracterizadas por um tom de fronteira denominado medial continuativo (TENANI, 2002), caracterizado por uma leve ascendência $(\mathrm{H} \%)$ em fronteira de I" e passível de ocorrência de pausa (SONCIN, 2012). Desse modo, em [o que se espera em diversas partes do país,] a inserção da vírgula indica uma fronteira com tom continuativo, indicando que a sentença não está completa.

Por se tratar também de um enunciado longo, 1 b) é segmentado em quatro sintagmas entoacionais. Ocorrências como estas não podem ser ignoradas, interpretadas apenas como um erro de pontuação, mas devem ser discutidas à luz de teorias fonológicas. É possível que uma prosódia implícita tenha motivado o escrevente a marcar fronteiras de sintagmas, pelo uso da vírgula.

c) "Em adição, os pais devem estar atentos aos elementos apropriados pelos seus filhos em propagandas, estimulando o espírito crítico deles, a contribuir para a futura cidadania que os espera."

Em 1 c) tem-se, novamente, uma oração que, por exercer a função de substantiva de um objeto indireto, é parte integrante da oração que a antecede, razão pela qual a vírgula não deve ser utilizada entre ambas. A justificativa para tal marcação pode ser melhor entendida ao se observar o enunciado que, por ser extenso, é segmentado em partes:

[Em adição]I [os pais devem estar atentos aos elementos apropriados pelos seus filhos em propagandas]I [estimulando o espírito crítico deles]I [a contribuir para a futura cidadania que os espera]I

Nespor e Vogel (1986) salientam que a reestruturação de Is é mais provável de ocorrer nos casos em que as estruturas dos enunciados têm extensão relativamente longa de I, velocidade 
relativamente lenta de fala e maior formalidade ou menor formalidade discursiva. No caso do trecho de 1 c) verificamos que a inserção da vírgula pelo escrevente é uma tentativa de marcar uma fronteira de I justamente devido à extensão do enunciado.

Categoria 2: vírgula separando sujeito de predicado

A gramática normativa é categórica ao pontuar que sujeito e predicado não podem ser separados por vírgula. Contudo não é o que se observa nos trechos apresentados a seguir retirados de redações nota mil do ENEM

a) O desenvolvimento econômico, virá como consequência.

Nessa situação, o escrevente demarca, pelo uso da vírgula, duas frases entoacionais. Embora neste caso, não se trate de uma frase longa que justifique a segmentação em duas partes, o escrevente o faz, evidenciando que ele identifica duas Is. Nesse caso, o uso da vírgula parece estar sendo guiado pela pausa entre sujeito e predicado que é comum na oralidade, o que reforça o fato de que, durante a fala, os indivíduos seguem inconscientemente regras fonológicas que estabelecem características prosódicas dos enunciados.

[O desenvolvimento econômico]I [virá como consequência]I

b) Os motivos para o fluxo migratório até então supracitados, dizem respeito às [...].

Segundo as normas da pontuação, o uso da vírgula, em 2 a) e em 2 b), é inadequado pois rompe o elo sintático existente entre o sujeito e o predicado. Considerando a hipótese de Cagliari (1989) de que os sinais de pontuação atuam como marcadores prosódicos, a pausa representada pela vírgula, especialmente em "b", pode ter sido motivada por aspectos sonoros de forma intuitiva por se tratar de um sujeito mais longo, o que, na modalidade oral, poderia, naturalmente, ocasionar essa pausa. No entanto, tal situação não justifica o uso da vírgula, sob o ponto de vista sintático da escrita. A segmentação a seguir diz respeito à demarcação de limites de fronteiras entoacionais evidenciados em b):

[Os motivos para o fluxo migratório até então supracitados]I [dizem respeito às]I

Em 2 b, o uso não convencional da vírgula após a palavra supracitados marca a fronteira prosódica de uma frase entoacional não final que se configura em decorrência da extensão do enunciado. Por se tratar de um enunciado longo, o escrevente divide o enunciado em duas frases entoacionais. Embora nem sempre os limites dos sintagmas entoacionais correspondem a uma pausa, a divisão entre sintagmas entoacionais, por vezes, obedece a condições fonológicas as quais "estabelecem que constituintes longos tendem a ser divididos" (FROTA, 2011, p. 45).

Categoria 3: vírgula antes da conjunção aditiva "e" com mesmo sujeito

Conforme as regras da gramatica normativa, não se usa vírgula antes da conjunção aditiva "e" que liga orações com o mesmo sujeito. Mas as análises realizadas mostram que apesar dessa proibição, a colocação da vírgula ocorre com frequência em textos que devem seguir a escrita padrão, conforme exemplos a seguir. 
a)“[...] A esperança é que nosso país respeite os direitos humanos o princípio da solidariedade entre os povos, e que honre a graciosa forma $[\ldots]$ ".

O uso da vírgula, nesse excerto, antes da conjunção "e", não é recomendado porque o sujeito das orações aditivas é o mesmo, isto é, o sujeito de "respeite" é também de "honre", qual seja "nosso país. Nesse caso, observamos também o uso indevido da vírgula, motivado pela prosódia, em função da complexidade sintática e da extensão do enunciado, marcando a pausa natural da fala nesse contexto enunciativo. A delimitação das frases entoacionais pelo escrevente da amostra 3 é a seguinte:

[A esperança é que nosso país respeite os direitos humanos o princípio da solidariedade entre os povos]I [e que honre a graciosa forma]I

Há, também em 3 a), condições fonológicas determinando a divisão dos constituintes. Por se tratar de um enunciado de estrutura sintática complexa e por se tratar de um enunciado longo, o escrevente viola as regras da pontuação e insere uma vírgula entre as duas frases entoacionais dividindo-as.

b) Com isso, o homem contemporâneo não almeja se deslocar em busca de um subemprego, e vem ao Brasil para contribuir como mais uma agente para o desenvolvimento do país.

O uso da vírgula, em 3 b), antes da conjunção “e”, conforme já esclarecido anteriormente, não é recomendado porque o sujeito das orações aditivas é o mesmo, isto é, "o homem contemporâneo" é sujeito de "almeja", "deslocar" e "vem". No entanto, o longo período leva o escrevente a dividi-lo em partes menores, como correria naturalmente se esse trecho fosse oralizado. A segmentação em frases entoacionais do trecho de 3 b) ocorreu como mostrado a seguir:

[Com isso]I [o homem contemporâneo não almeja se deslocar em busca de um subemprego]I [estimulando o espírito crítico deles]I [e vem ao Brasil para contribuir como mais uma agente para o desenvolvimento do país]I

Categoria 4: vírgula depois da conjunção explicativa "pois"

De acordo com a gramática normativa, não se deve colocar vírgula depois da conjunção explicativa "pois". Esse é pois mais um caso de uso indevido de vírgula identificado nas redações nota mil do ENEM. Veja exemplo a seguir:

a) “[...] a lei demanda maior fiscalização, pois, é preciso eliminar a habitual certeza de impunidade [...]."

Nesse trecho, observamos que a conjunção "pois" tem uma carga semântica de cunho explicativo e não conclusivo, como sugere, ao se apresentar entre vírgulas, não se trata, portanto, de uma conjunção coordenativa conclusiva. impunidade]I

[“a lei demanda maior fiscalização]I [pois]I [é preciso eliminar a habitual certeza de

Vê-se, claramente, em 4 a), que o escrevente delimita três frases entoacionais. O item "pois" entre vírgulas, constituindo uma frase entoacional, tem, no nosso entender, um caráter enfático: o escrevente chama a atenção para a justificativa que sucede o elemento "pois" enfatizado. Os dados 
encontram respaldo na fonologia prosódica segundo a qual os enunciados são organizados em estruturas prosódicas que abrangem o ritmo e a entoação das línguas. Os dados apresentados revelam que, assim como a estrutura prosódica determina possibilidades de realizações fonéticas dos elementos prosódicos de eventos de fala, ela subjaz, também, a possibilidades de registros de eventos escritos.

Categoria 5: vírgula separando nome e seu complemento

A contiguidade entre nome e seu complemento não pode ser interrompida com o uso da vírgula. Assim preconiza a gramática normativa. Contudo, essa é mais uma regra de uso de vírgula que às vezes não é atendida, conforme exemplos a seguir:

a) Nesse sentido, o Brasil é favorecido, com a entrada de mais indivíduos na população economicamente ativa (...).

No caso de 5 a), o usos da vírgula assinalado no período acima permite a seguinte observação: atentando-se para os complementos do termo "favorecido", o emprego da vírgula entre o nome e seus complementos quebra o princípio normativo segundo o qual, os termos integrantes de uma dada oração formam com ela uma unidade sintática e, por isso mesmo, não podem ser separados pela vírgula. No entanto, do ponto de vista do processamento da fala, a delimitação de um sintagma entoacional após a palavra favorecido é perfeitamente justificável, considerando que a oralização do trecho levaria o falante a realizar uma pequena pausa, absolutamente natural, após o trecho "o Brasil é favorecido". A segmentação do trecho apresentado em 5 a) é mostrado a seguir.

[Nesse sentido]I [o Brasil é favorecido]I [com a entrada de mais indivíduos na população economicamente ativa]I

Categoria 6: vírgula antes da conjunção "e" com caráter concluinte de uma enumeração

De acordo com as normas da gramática tradicional, não se deve usar vírgula antes da conjunção "e" ao término de uma enumeração. Todavia, a depender da organização prosódica da sentença é possível que se encontre esse sinal de pontuação, como se é possível observar no trecho a seguir:

a) (...) com a entrada de mais indivíduos na população economicamente ativa, e com a interação de sua sociedade com novas culturas, respeitando as diferenças.

Em 6 a), o uso da vírgula antes da conjunção "e" não se justifica do ponto de vista normativo da gramática. Embora isso possa ocorrer em situações específicas, o uso desse sinal de pontuação, no contexto em questão, é dispensável do ponto de vista da gramática tradicional, pois se trata de um complemento concluinte de uma enumeração. Ainda assim, a divisão dos constituintes do trecho supracitado pelo escrevente ocorreu do seguinte modo:

[com a entrada de mais indivíduos na população economicamente ativa]I [o Brasil é favorecido]I [e com a interação de sua sociedade com novas culturas]I [respeitando as diferenças]I

Assim como em 5 a), o uso inadequado de vírgulas pelo escrevente, em 6 a), é justificado por condições fonológicas que determinam a divisão dos constituintes. Trata-se de uma construção textual longa, o que faz com que o escrevente, motivado fonologicamente, quebre-o em várias partes. Esses 
dados são evidências de que a organização da linguagem em estruturas prosódicas também pode ser constatada nos enunciados escritos, bem como são indícios de como os escreventes organizam rítmica e entoacionalmente a sua escrita.

Os usos não-convencionais das vírgulas, apontados nos dados apresentados, são registros da imagem que os escreventes têm da linguagem, com base em seu modelo de fala, em suas práticas orais e escritas de uso da língua. (CHACON, 2001).

Categoria 7: vírgula antes de "que" com caráter restritivo

A vírgula antes de "que" com caráter restritivo é outro contexto de colocação desse sinal de pontuação que é proibido pela gramática. Contudo, ocorrências desses usos também foram encontradas nas redações notam mil do ENEM.

a) Até os brasileiros que saíram do país em busca de melhores condições estão retornando por acreditarem no potencial brasileiro. Por isso, é preciso aproveitar o momento oportuno, que traz vantagens econômicas e trocas culturais. [...]

Em 7 a), a última oração exerce a função de adjunto adnominal do antecedente "momento oportuno", com valor restritivo, constituindo-se numa oração subordinada adjetiva restritiva, razão pela qual não deve ser precedida por vírgula.

O escrevente do trecho ilustrado em 7 a) divide o enunciado em quatro constituintes, como pode ser observado a seguir:

[Até os brasileiros que saíram do país em busca de melhores condições estão retornando por acreditarem no potencial brasileiro]I [Por isso]I [é preciso aproveitar o momento oportuno]I [que traz vantagens econômicas e trocas culturais]I

Assim como a reestruturação de Is pode ocorrer de modo a segmentar o enunciado em várias Is, devido à extensão, como ocorre em $1 \mathrm{c}$ ), reestruturação de Is pode também ocorrer no sentido de diminuir a quantidade de Is do enunciado, como mostram os dados de Soncin e Tenani (2015), em que há a supressão de vírgula onde ela deveria constar, pelo fato de o escrevente unir Is de menor complexidade prosódica a Is de maior complexidade prosódica, formando, então, apenas uma I.

Embora do ponto de vista normativo, o uso da vírgula esteja incorreto, ele é justificável do ponto de vista da organização prosódica da fala. Conforme discutido, a frase fonológica, quando muito longa, pode passar por um processo de reestruturação e se transformar em diversas frases. Isso se dá, entre outras razões, pelo fato de a fala estar limitada por instâncias fisiológicas como a necessidade de pausas para a respiração. Ainda que se trate de dados de escrita, é muito provável que os escreventes se pautem no seu modelo de fala para espacializar a sua escrita.

Em geral, nos trechos discutidos, têm-se enunciados longos, cuja segmentação pode ser motivada por questões prosódicas, bem como pela consciência que os falantes/escreventes têm de instâncias fisiológicas durante a produção da fala (como a pausa para a respiração). A leitura, silenciosa ou em voz alta, desses enunciados muito provavelmente levaria os leitores a marcarem uma pausa exatamente no local onde os escreventes identificaram uma fronteira prosódica e a sinalizaram com a vírgula. Um trabalho interessante com esses tipos de dados envolveria uma manipulação dos mesmos para gravação e análise acústica. Uma possível proposta seria apresentar esses dados escritos a leitores (fluentes) em três condições experimentais para gravação da leitura: 1) os trechos sem qualquer marca de pontuação, 2) os trechos com a pontuação adequada do ponto de vista da gramática 
Volume 15 - Número 2 - ago/dez de 2020

normativa, 3) os trechos com a pontuação tal qual se encontra. Após gravação, uma análise acústica e entoacional poderiam dar respaldo às discussões aqui empreendidas.

\section{Discussões}

Conforme orientações do INEP, para alcançar a pontuação máxima na redação do ENEM, o candidato necessita demonstrar, em seu texto, "domínio da modalidade escrita formal da Língua Portuguesa" (INEP, 2013, p. 11). Para isso, é necessário que o escrevente siga à norma padrão, no que se refere, por exemplo, às regras de ortografia, pontuação, translineação, regência verbal e nominal, concordância verbal e nominal, dentre outros mecanismos importantes para uma boa fluência na escrita, sob o ponto de vista da norma culta. Ao serem avaliadas redações que obtiveram nota máxima segundo os critérios de correção estabelecidos pelo INEP, constatamos uso inadequado de vírgulas do ponto de vista da gramática normativa. Esse fato leva ao seguinte questionamento: que fato leva corretores de redações do ENEM a atribuírem nota máxima, ao quesito pontuação, em redações que apresentam pontuação não-convencional do ponto de vista da gramática normativa? $\mathrm{O}$ que leva escreventes ao erro quanto ao uso de vírgulas em suas redações?

As análises realizadas, no presente trabalho, evidenciam que há influência da organização prosódica da fala na escrita dos redatores do ENEM. É possível que a colocação das vírgulas seja um reflexo da prosódia implícita inscrita em seu pensamento durante a elaboração do texto que é concordante com a prosódia implícita do corretor durante a correção, fato que leva o profissional a avaliar como adequada a vírgula utilizada. Fodor (2005) argumenta que os falantes de uma língua possuem um fraseamento prosódico na mente que possibilita uma pausa ou outra interferência prosódica no processamento durante a leitura. Além disso, as pistas prosódicas costumam ser marcadas na leitura pela pontuação, quase sempre baseada nas pistas orais usadas pelos ouvintes. Considerando que os leitores, no decorrer da leitura silenciosa, naturalmente idealizam sobre o input escrito um delineamento prosódico implícito, parecido ao contorno daquele enunciado produzido oralmente, os corretores podem ser motivados a "aceitar", por assim dizer, as vírgulas, não se apercebendo de que, do ponto de vista da normatividade, os usos estão incorretos.

Essas informações levam a crer que, no momento da leitura das redações, influências do fraseamento prosódico, que é projetado também durante a leitura silenciosa, pode distrair os corretores, (assim como outros leitores), quanto à inadequação das vírgulas que marcam uma pausa que, possivelmente, seria necessária na oralização do enunciado, mas que não se justificam do ponto de vista normativo.

Os dados discutidos neste trabalho apontam para uma questão que é, ainda nos dias atuais, conflitante, qual seja, a relação entre fala e escrita. Os dados apontam que, apesar de língua falada e escrita serem sistemas distintos, eles são modos de manifestação da língua e mantêm interdependência entre si. Pode-se verificar a existência de uma escrita organizada ritmicamente (CHACON, 2001), na escrita dos redatores do ENEM, bem como a co-ocorrência de três materiais significantes que podem estar atuando na escrita dos redatores: o gesto, o material fônico-acústico (ritmo) e o material gráfico (CORRÊA, 2001). Assim, o uso não normativo da vírgula para indicar fronteiras prosódicas decorrentes de uma prosódica implícita é concordante com a hipótese de Cagliari (1989) de que a vírgula, assim como os outros sinais de pontuação, são marcadores prosódicos da escrita e deverão ter características prosódicas específicas acusticamente identificáveis, como demonstrado por Pacheco $(2002,2006)$. 
Volume 15 - Número 2 - ago/dez de 2020

\section{Conclusões}

Destacamos que, embora o estudo seja de caráter preliminar, necessitando de mais evidências que comprovem as hipóteses levantadas na pesquisa, os dados evidenciam que, de fato, há problemas em relação à utilização de vírgulas nas redações nota mil, injustificáveis do ponto de vista gramatical normativo. No entanto, os casos investigados revelam que as ocorrências obedecem a uma organização mental da prosódia da fala que é projetada para a escrita no intuito de manter a integridade dos constituintes prosódicos sendo, portanto, justificáveis do ponto de vista da gramática da língua. A não percepção dos "erros" de pontuação por parte dos corretores reforça a Hipótese da Prosódia Implícita segundo a qual uma prosódia é projetada sobre o material escrito durante a leitura silenciosa. Essa prosódia segue o nosso modelo de fala. Sendo assim, é possível que, motivados pela segmentação natural da fala (prosódia implícita), esses avaliadores não percebem a incorreção em relação à vírgula porque a pausa, que possivelmente ocorreria na leitura em voz alta exatamente no local de inserção da vírgula, é projetada também para a leitura silenciosa.

Destacamos que a vírgula é um sinal de pontuação que está, em geral, ligado a fatos sintáticos. No entanto, ele também pode exercer a função de marcador prosódico, como mostraram os nossos dados, nos quais se constituiu como um marcador prosódico por excelência, no sentido de demarcar pausas características de fronteiras de sintagmas entoacionais. Ressaltamos que este estudo possui um caráter inicial, passível de ser aprofundado e estendido a outros marcadores prosódicos e/ou aspectos, diante das diversas possibilidades de análise que o abjeto em questão proporciona. Sendo tais redações instituídas e utilizadas como modelo ou protótipo a ser seguido, os resultados iniciais desta investigação servirão para ampliar os estudos, pesquisas e reflexões a respeito das redações nota mil do ENEM, no sentido de (re)avaliar determinadas crenças e conceitos subjacentes a essa avaliação tão importante e decisiva para alunos oriundos da educação básica.

\section{Referências}

BADER, M. (1998) Prosodic influences on reading syntactically ambiguous sentences. In Fodor, J. D. \& Ferreira, F. (eds.) Reanalyses in sentence processing, Dordrecht: Kluwer Academic, 1-46. BALDWIN R. S.; COADY, J. M. Psycholinguistic Approaches to a Theory of Punctuation. Journal of Reading Behavior, Orlando, v. 10, n. 4, p. 363-375, 1978 . Doi: https://doi.org/10.1080/10862967809547290.

BECHARA, Evanildo. Moderna gramática portuguesa. 37. ed. rev., ampl. e atual. conforme o novo Acordo Ortográfico. Rio de Janeiro: Nova Fronteira. 2009.

BISOL, L. (org.) Introdução a estudos de fonologia do português brasileiro. Porto Alegre: Edipucrs, 2001.

BRASIL. Instituto Nacional de Estudos e pesquisas Educacionais Anísio Teixeira.Redação no ENEM 2017: cartilha do participante. 2017. Brasília: INEP, 2017. . Ministério da Educação, Instituto Nacional de Estudos e pesquisas Educacionais Anísio

Teixeira. Matriz de Referência ENEM. Brasília: Ministério da Educação, 2012.

CAGLIARI, L. C. Prosody and Literature: A Case Study of Chapter I from Women in Love by D. J. Lawrence. 28f. Relatório (Estágio Pós-Doutoral) - Linacre College, University of Oxford, Oxford, 2002b.

CAGLIARI, L.C. A estrutura prosódica do romance A Moreninha. 2002. 40f. Relatório (Estágio Pós-Doutoral) - Linacre College, University of Oxford, Oxford, 2002a.

CATACH, Nina (février 1980) La Ponctuation. In: Langue Française 45: 16-27. Paris: Larousse. CEGALLA, Domingos Paschoal. Novíssima gramática da língua portuguesa. 46. ed. São Paulo: Companhia Editora Nacional, 2005. 
Volume 15 - Número 2 - ago/dez de 2020

CHACON, L. Ritmo da Escrita. Uma organização do heterogêneo da linguagem. São Paulo: Martins Fontes, 1998.

CHEN, H. C.; CHAN, K. T.; TSOI, K. C. Reading selfpaced moving text on a computer display. Human Factors, New York, v. 30, n. 3, p. 285-291, Jun. 1988. Doiu: https://doi.org/10.1177/001872088803000303

COHEN, H.; DOUAIRE, J.; ELSABBAGH, M. The role of prosody in discourse. Brain and Cognition, San Diego, v. 46, n. 1-2, p. 73-81, jun./jul. 2001. Doi: https://doi.org/10.1016/S02782626(01)80038-5

CORRÊA, M. L. G. O modo heterogêneo de constituição da escrita. São Paulo: Martins Fontes, 2004.

CUNHA, Celso Ferreira; CINTRA, Luís Filipe Lindley. Nova Gramatica do Português. Contemporâneo. Rio de Janeiro: Nova Fronteira, 3a ed. 2001.

FODOR, J. D. A Psicolingüística não pode escapar da prosódia. In: MAIA, Marcus \& FINGER, Ingrid. Processamento da Linguagem. Pelotas: Educat, 2005.

FODOR, J. D. Psycholinguistics cannot escape prosody. In: PROCEDINGS OF SPEECH PROSODY. Aix em Provance, França, 2002, p. 83-90.

FRAZIER, L. On Comprehending Sentences: Syntactic parsing strategies. Ph.D. Dissertation, University of Connecticut, 1979.

FROTA, Sónia. Fonética: Prosódia. Relatório. Universidade de Lisboa, 2011. Disponível em: https://labfon.letras.ulisboa.pt/personal/sfrota/PGLing/Relatorio Prosodia Frota 2011.pdf.

JORNAL GLOBO G1. Disponível em: < $\underline{\text { http://g1.globo.com/pb/paraiba/noticia }>, 2015 . A c e s s o ~ e m ~}$ 20 de jan.2019

KONDO, T.; MAZUKA, R. Prosodic Planning While Reading Aloud: On-line Examination of Japanese Sentences. Journal of Psycholinguistic Research, Warsaw, v. 25, n. 2, p. 357- 381, 1996. LEHISTE, I. 1973. Phonetic disambiguation of syntacticambiguity. Glossa, 7, 107-122.

MAGALHÃES et.al. O processamento prosódico gráfico de sentenças ambíguas na leitura silenciosa de surdos bilingues. Journal of Sciences 5 (1): p. 17-27, 2016.

NESPOR, M; VOGEL, A. Prosodic Phonology. Dordrecht-Holland: Foris Publications, 2007.

PACHECO, V. Estudo dos marcadores prosódicos através de uma investigação acústicoperceptual de textos lidos por falantes do português do Brasil. 2003. 132f. Dissertação (Mestrado em Linguística) - Instituto de Estudos da Linguagem, Universidade Estadual de Campinas,

PACHECO, V. O efeito dos estímulos auditivo e visual na percepção dos marcadores prosódicos lexicais e gráficos usados na escrita do português brasileiro. 2006. 349f. Tese (Doutorado em Linguística) - Instituto de Estudos da Linguagem, Universidade Estadual de Campinas, Campinas, 2006.

ROCHA LIMA, Carlos Henrique. Gramática normativa da língua portuguesa. Rio de Janeiro, 1964.

SELKIRK, E. Sentence prosody: intonation, stress and phrasing. In J. Goldsmith (Ed.), The Handbook of Phonological Theory. London: Blackwell, 1995.

SONCIN, G.;TENANI, L. Emprego de vírgula e prosódia do Português Brasileiro. Filol. Linguíst. Port., São Paulo, v. 17, n. 2, p. 473-493, jul./dez. 2015. 